\title{
Activation of the Nociceptin Opioid System in Rat Sensory Neurons Produces Antinociceptive Effects in Inflammatory Pain: Involvement of Inflammatory Mediators
}

\author{
Yong Chen ${ }^{\star}$ and Claudia Sommer \\ Department of Neurology, University of Würzburg, Würzburg, Germany
}

Despite a large body of literature on the nociceptin (NC) opioid system in pain modulation, the mechanism of action of NC remains largely unexplored. Here, we investigated the role and mode of action of the spinal NC system in inflammatory pain. Preemptive intrathecal administration of NC attenuated thermal hyperalgesia and mechanical allodynia in rats with intraplantar complete Freund's adjuvant (CFA) injection. By using immunohistochemistry in L4 dorsal root ganglion (DRG) neurons, a marked increase of NC and ORL1 receptor immunoreactivity was detected following CFA. Intrathecal administration of NC attenuated the CFA-induced increases of calcitonin gene-related peptide, transient receptor potential vanilloid-1, and tumor necrosis factor- $\alpha$ in DRG neurons. Real-time reverse transcriptionpolymerase chain reaction showed that NC reduced the up-regulation of inducible nitric oxide synthase mRNA but not that of neuronal nitric oxide synthase mRNA in spinal cord segments after CFA. Furthermore, [Nphe1] NC(1-13) NH2, a selective opioid receptor-like 1 (ORL1) receptor antagonist, significantly antagonized the effects of NC on pain modulation and on the expression of inflammatory mediators, indicating a specific NC action through the ORL1 receptor. Together, these findings reveal novel mechanisms by which the NC system produces analgesia. ๑) 2007 Wiley-Liss, Inc.

Key words: nociceptin; opioid receptor-like 1 receptor; pain; dorsal root ganglia; spinal cord; inflammatory mediators

Injection of complete Freund's adjuvant (CFA) into an animal's hindpaw produces pain behavior and inflammation characterized by thermal hyperalgesia, mechanical allodynia, and edema (Banner et al., 1998). Accompanying the behavioral changes are alterations in the discharge properties of afferent neurons as well as changes in the levels of messenger molecules. Numerous studies have established that peripheral inflammation can induce upregulation of inflammatory mediators such as calcitonin gene-related peptide (CGRP; Nahin and Byers, 1994), proinflammatory cytokines (Sommer and Kress, 2004), and nitric oxide synthase (NOS; Wu et al., 1998; Tao et al., 2003) in dorsal root ganglion (DRG) neurons and in the spinal cord, all of which have well-described roles in the generation or maintenance of inflammatory pain.

Nociceptin (NC; Meunier et al., 1995), alias orphanin FQ (OFQ; Reinscheid et al., 1995), is an endogenous ligand for the recently discovered fourth member of the opioid receptor family, namely, the opioid receptor-like 1 (ORL1) receptor. NC shows structural similarities to the opioid peptide dynorphin A, but it has low affinity to $\mu, \delta$, and $\kappa$ receptors. By activating the ORL1 receptor, NC can produce analgesic effects at the spinal level (Calo et al., 2000; Xu et al., 2000; Mogil and Pasternak, 2001). A preemptive analgesic effect of NC was shown in the animal model of chronic constriction injury (CCI) of neuropathic pain (Yamamoto et al., 2000). Preemptive analgesia is the phenomenon whereby administration of analgesics prior to painful stimuli can reduce perceived pain for a duration that far outlasts the expected pharmacological effect of the analgesic drug. This prolonged duration of action is thought to occur because the analgesic medications prevent or blunt the establishment of central sensitization evoked by nociceptive input to the spinal cord (Woolf and Chong, 1993). Whether NC also produces preemptive analgesia in chronic inflammatory pain is as yet unknown. It has been documented that various inflammatory mediators are involved in pain modulation by opioids and that opioids exert antiinflammatory effects by influencing the expression of these mediators

Contract grant sponsor: University of Würzburg.

*Correspondence to: Yong Chen, PhD, Neurologische Klinik der Universität, Josef-Schneider-Str. 11, 97080 Würzburg, Germany.

E-mail: chen_y@klinik.uni-wuerzburg.de

Received 25 August 2006; Revised 2 January 2007; Accepted 6 January 2007

Published online 23 March 2007 in Wiley InterScience (www. interscience.wiley.com). DOI: 10.1002/jnr.21272 
(Laughlin et al., 2000; Walker, 2003; Rittner and Stein, 2005). However, very little is known about the involvement of inflammatory mediators in pain modulation of the NC/ORL1 receptor opioid system.

During inflammation, hyperalgesic mediators such as cytokines, chemokines, nerve growth factor, prostaglandins, and NOS are liberated. At the same time, analgesic mediators such as peptides, somatostatin, endocannabinoids, and antiinflammatory cytokines are also produced, which counteract pain. Synthesized in the DRG, opioids are transported to the peripheral and central terminals of sensory neurons, where they produce antinociceptive actions (Levine et al., 1993). NC (Rosen et al., 2000) and the ORL1 receptor (Jia et al., 1998) are increased in the spinal cord after hind paw inflammation. We could recently show that NC and the ORL1 receptor were also up-regulated in the late phase of CFAinduced inflammation in DRG neurons (Chen and Sommer, 2006); however, information on their expression in DRG neurons in the early phase of inflammation is lacking.

We therefore assessed the effects of preemptive intrathecal administration of $\mathrm{NC}$ on the development of CFA-induced pain. We then determined $\mathrm{NC}$ and ORL1 receptor expression in DRG neurons at an early time point after inflammation and investigated whether exogenous NC pretreatment affects the CFA-induced increase of inflammatory mediators in the DRG and spinal cord. These results were presented in part at the Meeting of the Society for Neuroscience, Washington, DC, 2005.

\section{MATERIALS AND METHODS}

\section{Animals}

Male Sprague-Dawley rats (280-320 g; Charles River Germany) were used in all experiments. Animals were housed on a 14:10-hr light:dark cycle, with standard rodent chow and water available ad libitum. All experiments were approved by the Bavarian state authorities.

\section{Intrathecal Catheterization and Drug Delivery}

A PE10 catheter was implanted in the lumbar subarachnoid space during deep isoflurane anesthesia according to a method described previously (Yaksh and Rudy, 1976). Animals were allowed to recover for at least 5 days before experiments. Those rats exhibiting postoperative neurological deficits (e.g., paralysis) or poor grooming were euthanized. NC and the selective ORL1 receptor antagonist [Nphe1]NC (1-13)NH2 (Sigma) were dissolved in $0.9 \%$ saline and injected intrathecally in $10 \mu \mathrm{l}$, followed by a $10-\mu \mathrm{l}$ saline flush. Ten minutes later, rats were lightly anesthetized with ether and received $50 \mu \mathrm{l}$ of CFA (Mycobacterium tuberculosis; Difco Laboratories, Detroit, MI; diluted 1:1 with PBS, $2 \mathrm{mg} / \mathrm{ml}$ ) subcutaneously in the intraplantar surface of one hind paw. In the antagonist experiments, [Nphe1] NC(1-13)NH2 $(45 \mu \mathrm{g})$ was administered $5 \mathrm{~min}$ before NC $(30 \mu \mathrm{g})$. Control groups were lightly anesthetized with ether and received the same volumes of normal saline.

\section{Behavioral Testing}

Sensitivity to noxious heat was assessed with the device of Hargreaves et al. (1988), purchased from Ugo Basile (Comerio, Italy). A radiant heat source was focused on the plantar surface of the hindpaw, and the time from the initiation of the radiant heat until paw withdrawal latency (PWL) was measured automatically. A maximal cutoff of $25 \mathrm{sec}$ was used to prevent tissue damage. Each paw was tested three times; the mean withdrawal latency was calculated. The interval between two trials on the same paw was at least $5 \mathrm{~min}$.

Mechanical sensitivity was determined by probing the plantar surface of the hindpaw with an electronic von Frey hair (Ugo Basile). The tip of the device was positioned at the plantar surface and held there for $2 \mathrm{sec}$. The force (in g) of pressure at which the rat withdrew the hindpaw was recorded automatically. Testing was performed three times and mean values were calculated. The time interval between two trials was at least $3 \mathrm{~min}$ on the same paw. Animals were tested in random order to minimize bias of unblinded testing.

\section{Immunohistochemistry}

The ipsilateral L4 DRG from saline-treated rats, from rats 1 day and 7 days after CFA treatment with preemptive i.t. NC $(30 \mu \mathrm{g})$ or sham treatment (i.t. normal saline), and from rats 1 day after CFA treatment with preemptive coadministration of i.t. [Nphe1]NC(1-13) $(45 \mu \mathrm{g})$ and $\mathrm{NC}(30 \mu \mathrm{g})$ were removed. The tissues were mounted in Tissue Tek OTC (Dialec, Hallstadt, Germany) embedding compound, quickly frozen in liquid nitrogen, and stored at $-80^{\circ} \mathrm{C}$. DRGs were sectioned on a cryostat at a thickness of $10 \mu \mathrm{m}$. Sections were thaw-mounted onto Superfrost Plus slides (Langenbrinck, Teningen, Germany), air dried for $30 \mathrm{~min}$, postfixed for 10 min in acetone at $-20^{\circ} \mathrm{C}$, and blocked with $10 \%$ BSA/PBS for $30 \mathrm{~min}$. The following antibodies were used for DRG immunofluorescence: polyclonal rabbit antinociceptin (1:800; Chemicon, Temecula, CA), polyclonal goat anti-KOR3 (alias polyclonal goat anti-ORL1 receptor; 1:250; Santa Cruz Biotechnology, Santa Cruz, CA), polyclonal sheep antiactivating transcription factor 3 (ATF3, 1:100; Biogenesis, Poole, United Kingdom), monoclonal goat antitumor necrosis factor- $\alpha$ (TNF- $\alpha$; 1:100; Linaris, Wertheim, Germany), monoclonal mouse anti-IL-10 (1:20; BD PharMingen, San Diego, CA), polyclonal rabbit anti-CGRP (1:500; Peninsula, Belmont, $\mathrm{CA})$, and polyclonal rabbit antitransient receptor potential vanilloid-1 (TRPV-1; 1:500; Affinity BioReagents, Hamburg, Germany). Sections were incubated at $4^{\circ} \mathrm{C}$ for $24 \mathrm{hr}$, washed three times for $10 \mathrm{~min}$ each in PBS, and incubated for $2 \mathrm{hr}$ in a Cy3-conjugated or Cy2-conjugated secondary $\mathrm{AB}$ (1:100; Dianova, Hamburg, Germany). After immunostaining, they were viewed and digitized with a Zeiss Axiophot 2 microscope and quantitatively analyzed in Image Pro Plus (version 4.0; Media Cybernetics, Leiden, The Netherlands). All sections were captured with the camera settings held constant. The examiner was unaware of the identity of the slides. Neuronal cell bodies were identified by the typical morphology and the presence of a nucleus. The density threshold for the positive immunoreactivity was determined by averaging two or three cell bodies in each section that were judged to be minimally 
positive. All neurons for which the mean density exceeded the threshold were counted as positive, and the positive cells were expressed as a percentage of total counted DRG neurons [\%= (positive cells/total counted cells) $\times 100]$. The area of the NC- and ORL1 receptor-IR neuronal profiles was measured and displayed as size frequency distributions. Percentages were calculated for each DRG as follows: $\%=$ (positive cells within a size range/total positive cells) $\times 100$. A stereological approach was not used in this study, so quantification of neuronal profile area may represent a biased estimate. However, all sections were treated in exactly the same way, such that the comparison between groups should be valid. The number of neuronal profiles labeled for both ATF3 and NC or ORL1 receptor, relative to the total number of $\mathrm{NC}$ or ORL1 receptorpositive profiles, was obtained from double-labeled sections. To distinguish cell-size-specific changes, we characterized the DRG neurons as small $\left(<600 \mu^{2}\right)$, medium-sized (600-1,200 $\left.\mu \mathrm{m}^{2}\right)$, and large $\left(>1,200 \mu \mathrm{m}^{2}\right)$ neurons, according to their cross-sectional area (Schäfers et al., 2003). Controls for all immunohistochemical stains were performed by omission of the primary $\mathrm{AB}$ and for the anticytokine antibodies by preabsorption studies (Schäfers et al., 2003).

\section{Real-Time PCR}

Because NOS immunostaining using different antibodies [polyclonal rabbit anti-iNOS and anti-nNOS (Santa Cruz Biotechnology) and mouse monoclonal anti-iNOS and antinNOS (BD Biosciences)] in DRG and in spinal cord of control and experimental animals was unreliable in our laboratory, we used real-time PCR to detect the expression of NOS mRNA in spinal cord. In separate groups of rat treated either with i.pl. and i.t. saline only or with i.pl.CFA and preemptive i.t. NC $(30 \mu \mathrm{g})$ or sham treatment (i.t. normal saline), the L45 spinal cord segments were harvested 1 day after i.pl. injections. Tissue homogenization and RNA isolation from spinal cord were performed as described previously (Kleinschnitz et al., 2004). In brief, total RNA from each tissue was prepared with the Trizol reagent (Invitrogen Germany) and was quantified spectrophotometrically. Tissues were homogenized with a Polytron homogenizer (Kinematica Germany). Relative nNOS- and iNOS-mRNA levels were quantified with realtime PCR using the fluorescent TaqMan technology. Five hundred nanograms of total RNA were reverse transcribed (TaqMan Reverse Transcription Reagents; Applied Biosystems Germany) using random hexamers. PCR primers and probes specific for rat nNOS, iNOS, and 18s rRNA were obtained as TaqMan Predeveloped Assay Reagents for gene expression (Applied Biosystems IDs for nNOS and iNOS primers: Rn00583793_m1 and Rn00561646_m1). 18s rRNA was used as an endogenous control. PCR was performed with equal amounts of cDNA in the GeneAmp 7700 sequence detection system (Applied Biosystems) using TaqMan Universal PCR Master Mix (Applied Biosystems). Reactions (total volume $50 \mu \mathrm{l}$ ) were incubated at $50^{\circ} \mathrm{C}$ for $2 \mathrm{~min}$, at $95^{\circ} \mathrm{C}$ for $10 \mathrm{~min}$, followed by 40 cycles of $15 \mathrm{sec}$ at $95^{\circ} \mathrm{C}$ and $1 \mathrm{~min}$ at $60^{\circ} \mathrm{C}$. Water controls were included to ensure specificity. Each sample was measured in triplicate, and data points were examined for integrity by analysis of the amplification plot. The compar- ative $\mathrm{Ct}$ method was used for relative quantification of gene expression. The amount of nNOS and iNOS mRNA, normalized to the endogenous control (18s rRNA) and relative to a calibrator (tissue from healthy animals), is given by $2^{-\Delta \Delta \mathrm{Ct}}$, with $\mathrm{Ct}$ indicating the cycle number at which the fluorescence signal of the PCR product crosses an arbitrary threshold set within the exponential phase of the PCR, and $\Delta \Delta \mathrm{Ct}$ $=\left[\left(\mathrm{Ct}_{\text {target }}\right.\right.$ (unknown sample) $-\mathrm{Ct}_{\mathrm{end}}$ control (unknown sample) $\left.)\right]-$ $\left[\left(\mathrm{Ct}_{\text {target (calibrator sample) }}-\mathrm{Ct}_{\text {end control (calibrator sample) }}\right)\right]$.

\section{Data Analysis}

Results are presented as means \pm SEM. Unpaired $t$-tests or repeated-measures ANOVAs followed by Tukey post hoc test were used for differences between groups as appropriate. $P<0.05$ was considered statistically significant.

\section{RESULTS}

\section{Pretreatment With NC Attenuates CFA-Induced Pain}

Pain thresholds were not significantly changed after intraplantar saline injections (data not shown). After CFA, significant heat hyperalgesia and mechanical allodynia were observed on the injected side throughout the whole observation period (Fig. 1).

Pretreatment of NC at a dose of $30 \mu \mathrm{g}$ significantly attenuated thermal hyperalgesia from $2 \mathrm{hr}$ to 3 days after CFA (Fig. 1A). NC did not alter thermal pain thresholds at a dose between $3 \mu \mathrm{g}$ and $10 \mu \mathrm{g}$ at any time point studied except for $10 \mu \mathrm{g} \mathrm{NC}$ on day 3 (Fig. 1A). CFAinduced mechanical allodynia caused by CFA was reduced by $\mathrm{NC}$ in a dose-dependent manner between $10 \mu \mathrm{g}$ and $30 \mu \mathrm{g}$; Fig. 1B), and $3 \mu \mathrm{g} \mathrm{NC}$ also increased mechanical pain thresholds at the time points $6 \mathrm{hr}$ and 2 days (Fig. 1B).

[Nphe1]NC(1-13)NH2, a selective ORL1 receptor antagonist (Calo et al., 2000), significantly reversed the analgesic effect of $\mathrm{NC}$ on thermal hyperalgesia and mechanical allodynia after CFA (Fig. 1C,D). It did not alter pain thresholds of control animals or of rats treated with i.pl. CFA only (Fig. 1E,F).

\section{NC and ORL1 Receptor Immunoreactivity Are Increased in DRG Neurons After CFA}

In control DRG, 31\% of neurons displayed immunoreactivity (IR) for $\mathrm{NC}$ and $33 \%$ for ORL1 receptor (Figs. 2A,D, 3A,G). On day 1 after CFA, a significant increase of NC- and ORL1 receptor-IR was observed in the ipsilateral DRG $(60 \%$ and $52 \%$, respectively; $P<$ 0.001; Figs. 2A,D, 3D,J), showing the same direction of change as previously shown in the late phase of CFAinduced inflammation (Chen and Sommer, 2006). Specifically, the percentage of NC-IR was reduced in small neurons $\left(<400 \mathrm{~mm}^{2}, P<0.001\right)$ and increased in medium-sized ones $\left(600-800 \mu^{2}, P<0.01\right)$; furthermore, there was a trend to increased expression in large neurons. Similarly, there was a shift of ORL1 receptor-IR, although this did not achieve statistical significance (Figs. 2C,F, 3A,D, G,J). 

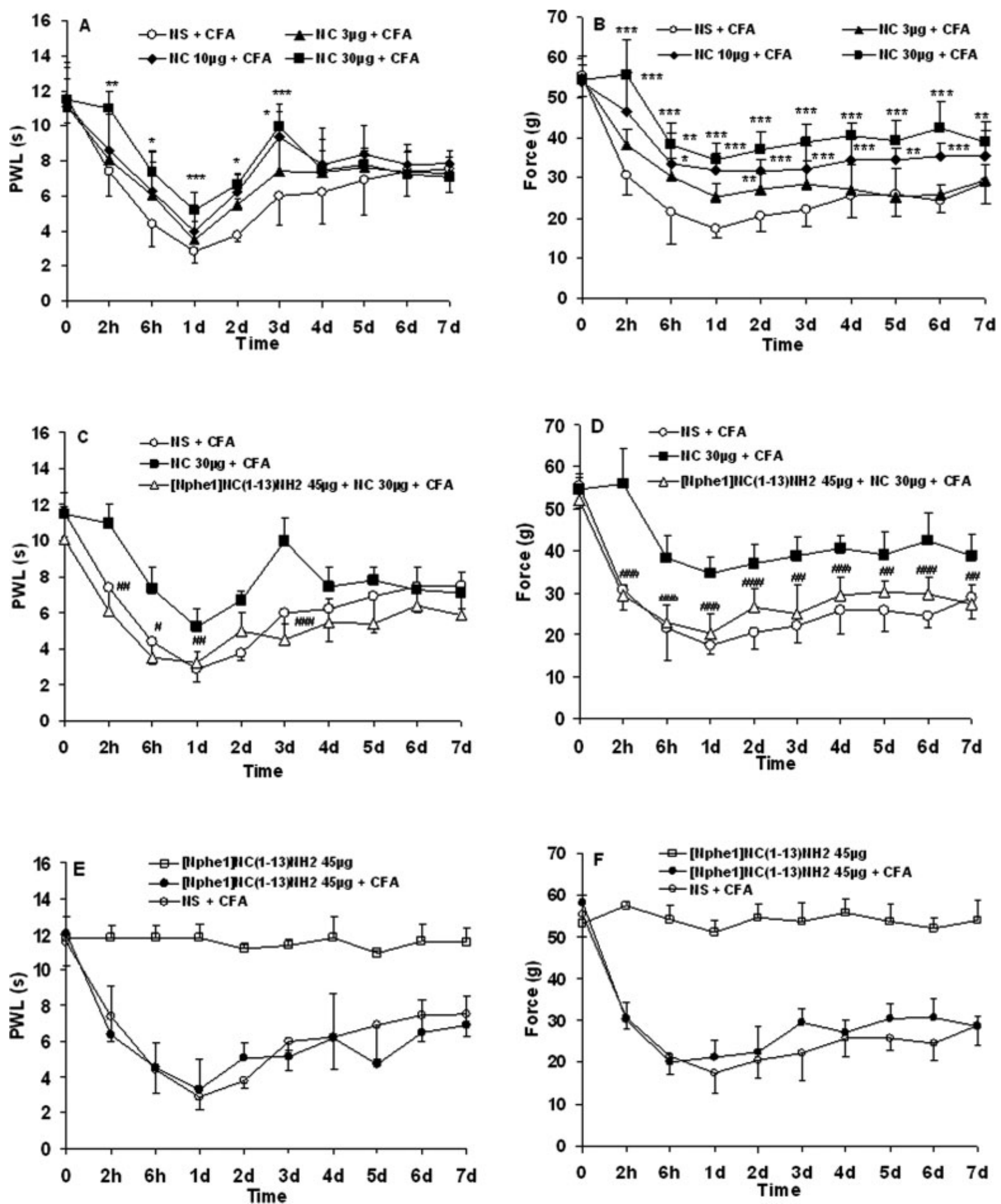

Fig. 1. Effects of preemptive i.t. NC on ipsilateral thermal hyperalgesia (A) and mechanical allodynia $(\mathbf{B})$ caused by CFA $\left({ }^{\star} P<0.05\right.$, $\star \star P<0.01$, and $\star \star \star P<0.001$, compared with CFA group, repeated-measures ANOVA followed by Tukey test). The antiinflammatory effects of NC was significantly antagonized by [Nphe1]NC(1-13) NH2 (C,D; ${ }^{\#} P<0.05,{ }^{\# \#} P<0.01$, and ${ }^{\# \# \#} P<$

0.001, compared with $\mathrm{NC}+\mathrm{CFA}$ group, repeated-measures ANOVA followed by Tukey test). [Nphe1]NC(1-13)NH2 did not alter baseline pain thresholds of control animals and CFA-induced hyperalgesia (E,F; $\mathrm{n}=6$ for each group). PWL, paw withdrawal latency upon heat stimulation; Force, force of the von Frey hair at which the rat withdraws the paw. 

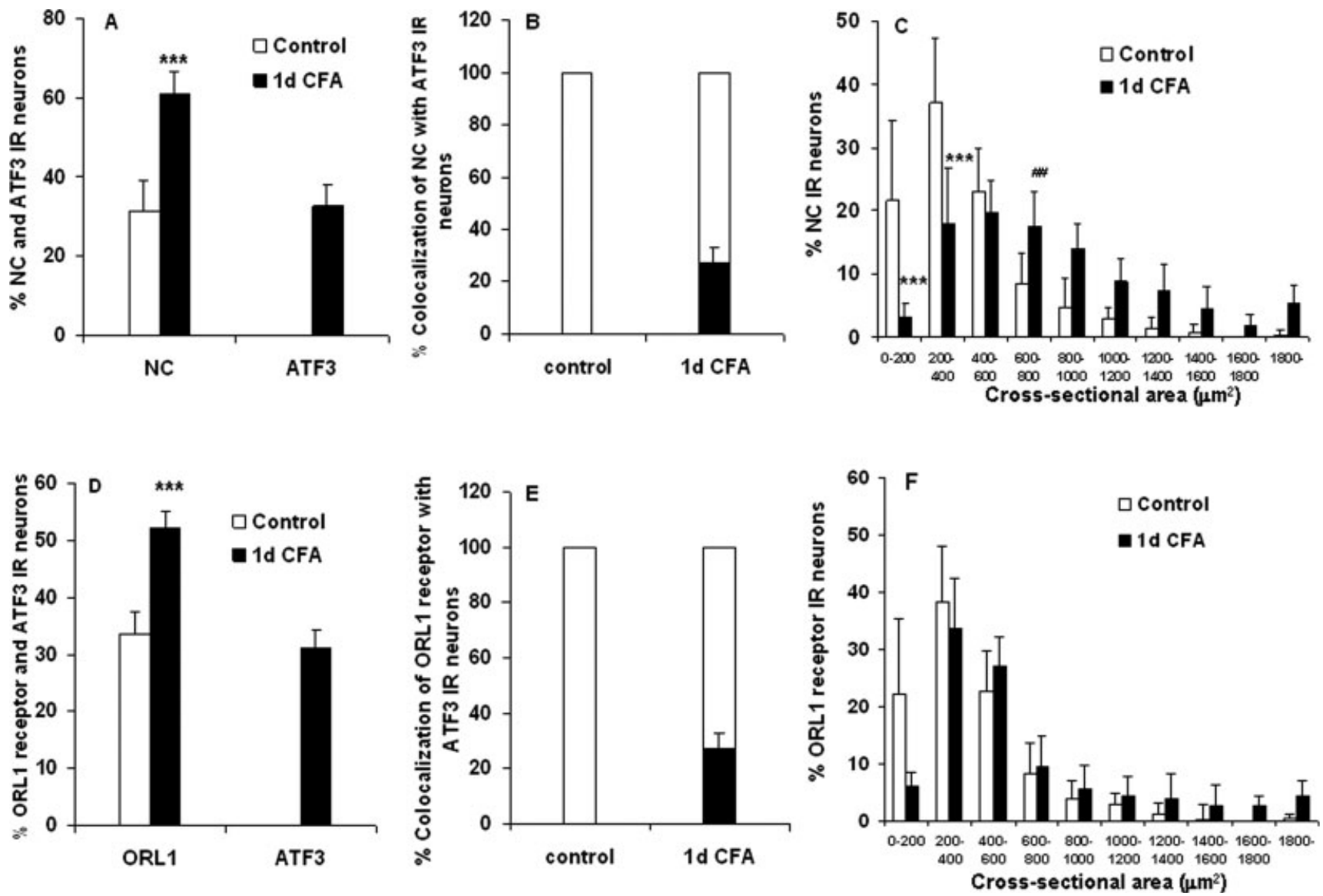

Fig. 2. Percentage of NC-IR (A) and ORL1 receptor-IR (D) in ipsilateral L4 DRG neurons in controls $(\mathrm{n}=4)$ and 1 day after CFA $(n=4)$. Percentage of ATF3-IR neurons in the same sections as visualized after double staining. NC-IR (A) and ORL1 receptor-IR (D) were increased 1 day after CFA $(\star \star \star P<0.001$ compared with control, unpaired $t$-test). Colocalization of NC (B) or ORL1 receptor (E) with ATF3. One day after CFA, in 26-27\% of neurons NCand ORL1 receptor-IR were colocalized with ATF3. Size-frequency

ATF3 was used as a marker for injured neurons (Tsujino et al., 2000). As expected, none or very few ATF3-IR neurons were found in control DRG (Figs. 2A,D, 3B,H), and $31 \%$ of neurons displayed ATF3-IR 1 day after CFA (Figs. 2A,D, 3E,K). NC- and ORL1 receptor-IR were coexpressed with ATF3 in only about $25 \%$ of neuronal profiles 1 day after CFA, indicating the presence of $\mathrm{NC}$ and $\mathrm{ORL}-1$ receptor mostly in uninjured neurons (Figs. 2B,E, 3F,L).

\section{NC Pretreatment Reduces Proinflammatory Mediators in DRG Neurons After CFA}

Figures 4 and 5 illustrate that 40\%, 38\%, 25\%, and $24 \%$ of neurons showed IR for CGRP, TNF, TRPV-1, and IL-10 in control DRG, respectively. CGRP-, TNF-, and TRPV-1-IR were increased on day 1 (to 64\%, $63 \%$, and $53 \%$ ) and to a minor degree still on day 7 (54\%, 47\%, and 32\%) after CFA $(P<0.001$ and $P<$ histograms illustrating the distribution of cross-sectional areas of NCIR (C) and ORL1 receptor-IR (F). NC- and ORL1-IR were localized predominantly in small to medium-sized neurons. Note a size frequency shift of NC-IR away from small $\left(<400 \mu \mathrm{m}^{2}, \star \star \star P P<\right.$ 0.001 compared with control, repeated-measures ANOVA followed by Tukey test) to medium-sized (600-800 $\mu^{2},{ }^{\# \# P}<0.01 \mathrm{com}-$ pared with control) and tendentially to large neurons 1 day after CFA.

$0.01)$, whereas IL-10-IR was increased only on day 1 (37\% of positive neurons, $P<0.01$ ). In animals pretreated with $30 \mu \mathrm{g} N C$ i.t., the increase in CGRP-, TNF-, and TRPV-1-IR in DRG neurons after CFA was attenuated, with the exception of TRPV1 on day 7. The effects of NC were antagonized by the selective ORL1 receptor antagonist [Nphe1]NC(1-13)NH2. IL10-IR was not changed by NC and by coadministration of [Nphe1]NC(1-13)NH2 and NC.

\section{NC Pretreatment Reduces iNOS Up-Regulation in the Spinal Cord}

Quantification of mRNA by real-time RT-PCR showed a significantly increased expression of $\mathrm{nNOS}$ and iNOS mRNA in the L4-5 spinal cord 1 day after CFA. Up-regulation of iNOS, but not nNOS, mRNA was reduced in rats pretreated with $30 \mu \mathrm{g} \mathrm{NC}$ i.t. (Fig. 6). 

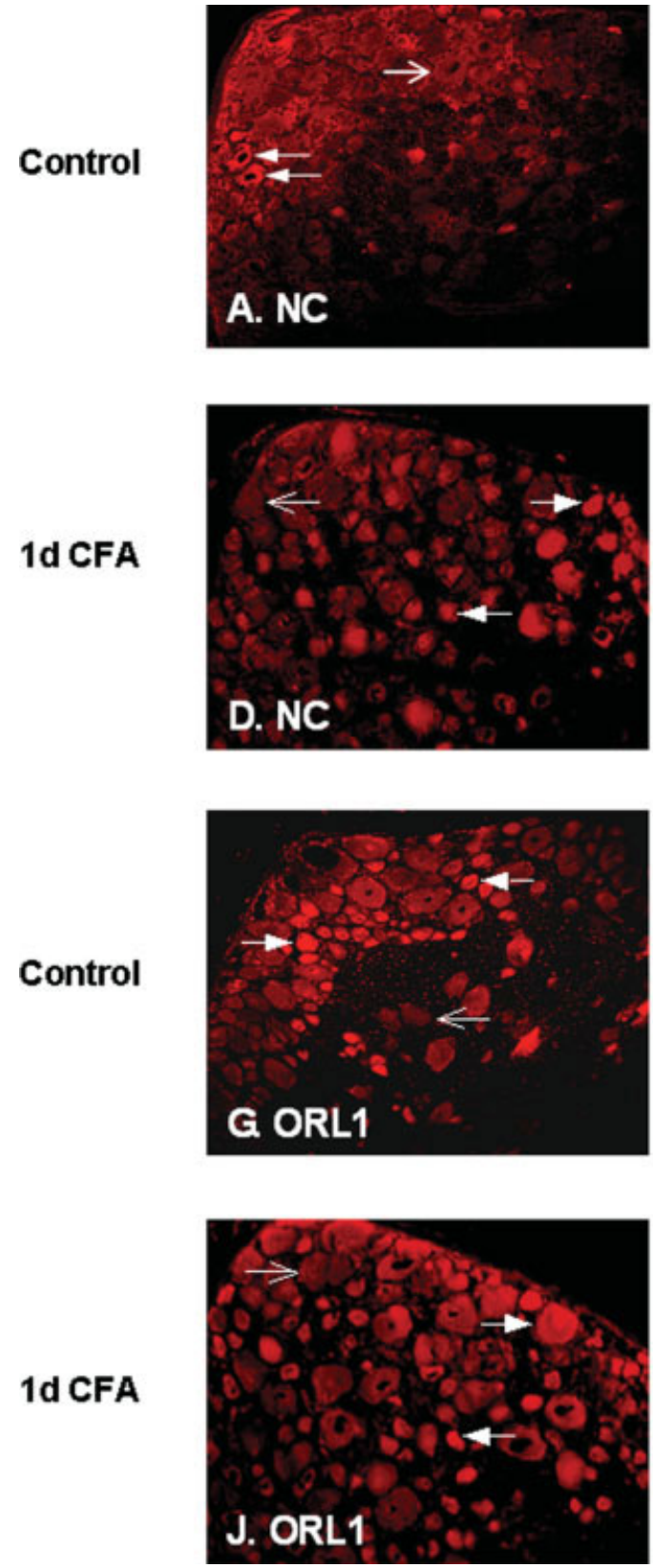

\section{B. ATF3}
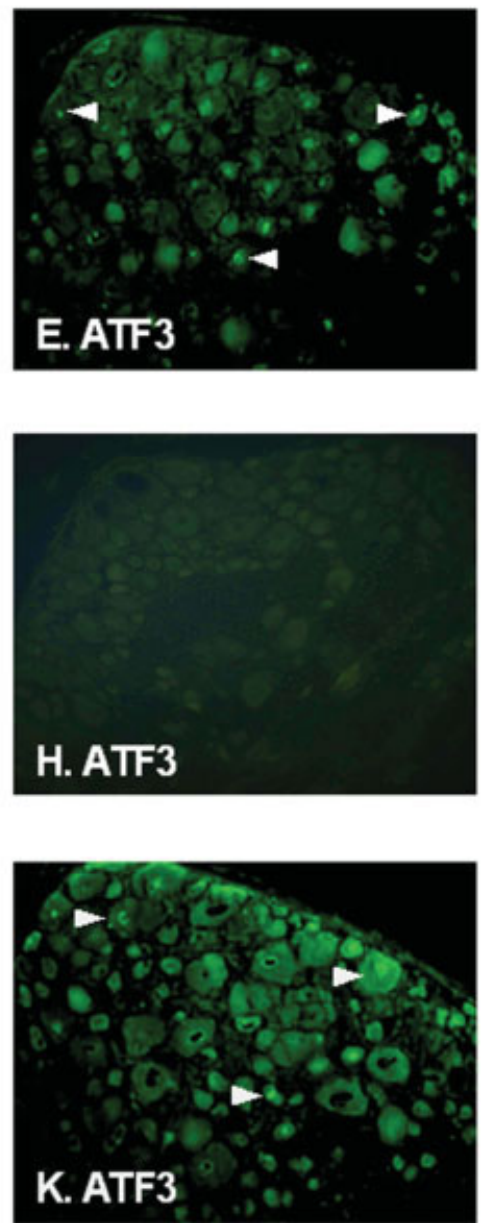
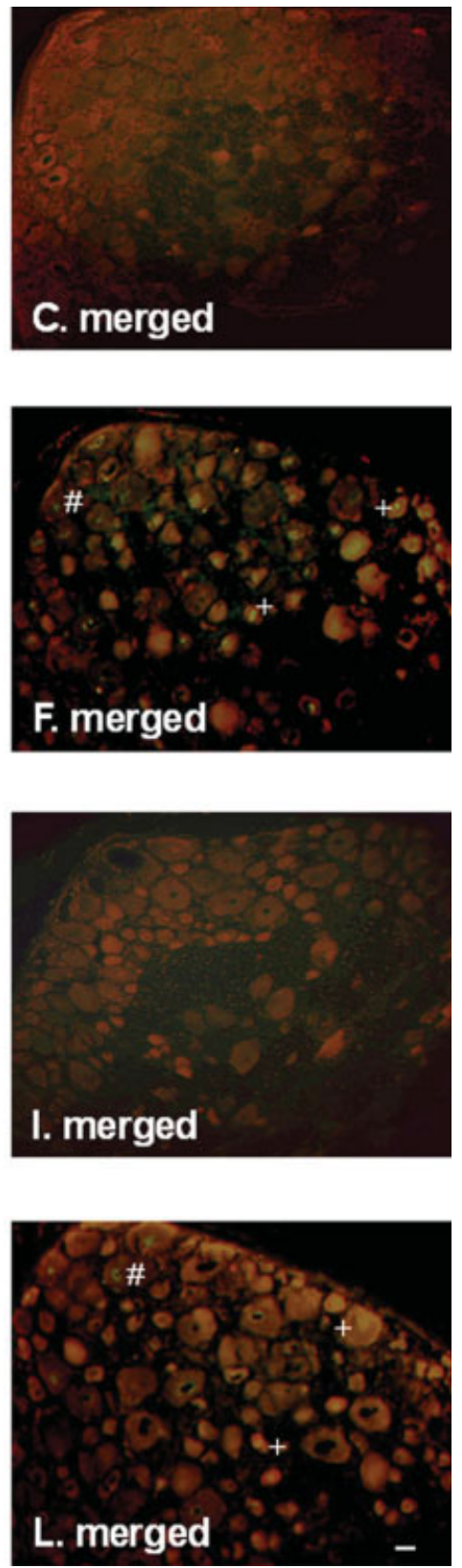

Fig. 3. Photomicrographs showing NC-, ORL1 receptor-, and ATF3-IR in ipsilateral L4 DRG from controls (A, $\mathbf{G}$ and $\mathbf{B}, \mathbf{H}$, respectively) and 1 day after CFA $(\mathbf{D}, \mathbf{J}$ and $\mathbf{E}, \mathbf{K}$, respectively). Solid arrows, open arrows, and arrowheads for NC- and ORL1 receptor-positive, NC- and ORL1 receptor-negative, and ATF3-positive, respectively. C,F,I,L: Merged images show neurons with double labeling ( + and \# for colocalization-positive and colocalization-negative respectively). Scale bar $=20 \mu \mathrm{m}$.

\section{DISCUSSION}

This series of experiments yielded the following major findings: 1) Preemptive administration of i.t. NC reduced hyperalgesia and allodynia after i.pl. CFA. 2) These effects were mediated through the ORL1 receptor. 3) NC- and ORL1 receptor-IR were increased in DRG neurons rapidly after CFA. 4) The change toward a proinflammatory profile in the DRG and spinal cord after CFA was blocked by NC pretreatment.

\section{NC Attenuates CFA-induced Inflammatory Pain}

Nociceptin can produce antinociception through pre- and postsynaptic mechanisms at the spinal level (Calo et al., 2000; Xu et al., 2000; Mogil and Pasternak, 

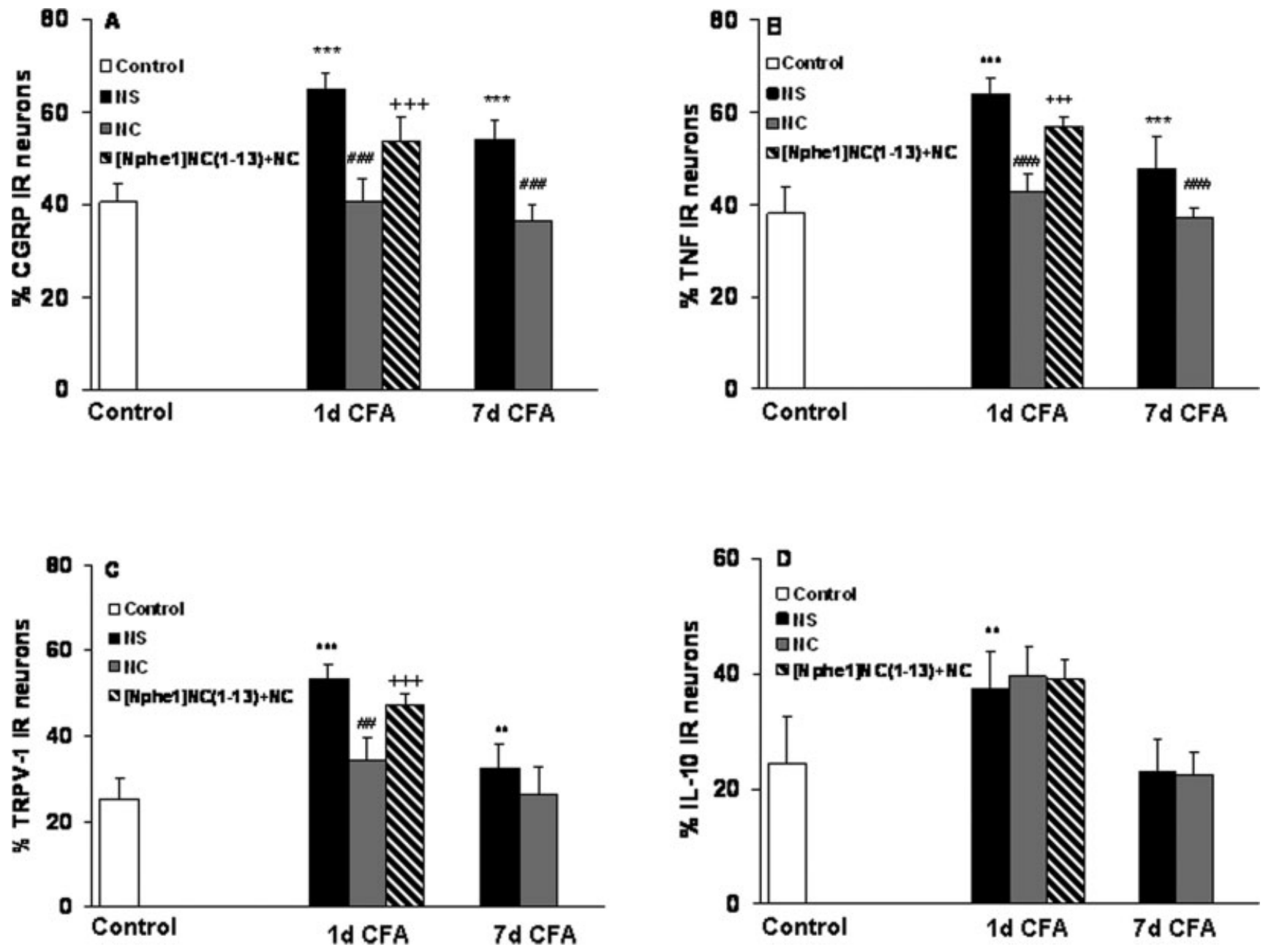

Fig. 4. Percentage of CGRP-IR (A), TNF-IR (B), TRPV-1-IR (C), and IL-10-IR (D) neuronal profiles in ipsilateral L4 DRG from controls and from rats 1 day and 7 days after CFA with and without NC $(30 \mu \mathrm{g})$ pretreatment and additional administration of the selective ORL1 receptor antagonist [Nphe1]NC(1-13)NH2 $(45 \mu \mathrm{g})$ on day 1. Percentages were increased after CFA, with the exception of IL-10 on day $7\left(\star \star P P 0.01\right.$ and ${ }^{\star \star \star} P<0.001$, compared with con-

2001). In the present study, NC at high doses reduced the development of thermal hyperalgesia and mechanical allodynia caused by i.pl. CFA in a long-lasting manner. The effects produced by NC were abolished by the selective ORL1 receptor antagonist [Nphe1]NC(113) $\mathrm{NH} 2$, indicating that the function of $\mathrm{NC}$ is mediated specifically through the ORL1 receptor pathway. The effect on mechanical allodynia lasted for up to 7 days after CFA, which is longer than would have been expected considering the half-life of NC and its degradation by peptidases (Terenius et al., 2000). In view of the present findings, we conclude that NC prevented the up-regulation of inflammatory mediators such as CGRP, TNF, TRPV1, and iNOS, which in turn lead to a longlasting attenuation of inflammatory pain. It is noteworthy that preemptive i.t. administration of $\mathrm{NC}$ reduced

trol). Aside from IL-10, the changes were significantly attenuated by NC with the exception of TRPV-1 on day $7\left({ }^{\# \#} P<0.01\right.$ and ${ }^{\# \# \#} P$ $<0.001$, compared with CFA group). The effect of NC could be antagonized by $[\mathrm{Nphe} 1] \mathrm{NC}(1-13) \mathrm{NH} 2\left({ }^{+++} P<0.001\right.$, compared with NC group) Repeated-measures ANOVA followed by Tukey test was used to detect differences between groups ( $n=4-6$ for each group).

c-Fos expression, a marker of activation of nociceptive neurons, in spinal cord $2 \mathrm{hr}$ after CCI (Yamamoto et al., 2000). Accordingly, it is conceivable that pretreatment of NC can prevent or blunt spinal facilitation evoked by nociceptive input to the spinal cord and thus produce a long-lasting effect.

\section{Expression of NC and ORL1 Receptor in DRG Neurons}

Previous studies on the expression of NC and ORL1 receptor after inflammation focused on their expression in the spinal cord (Rosen et al., 2000; Jia et al., 1998). Our data reveal that NC and ORL1 receptor are up-regulated in DRG not only in the late phase of CFA-induced inflammation (Chen and Sommer, 


\section{Control}

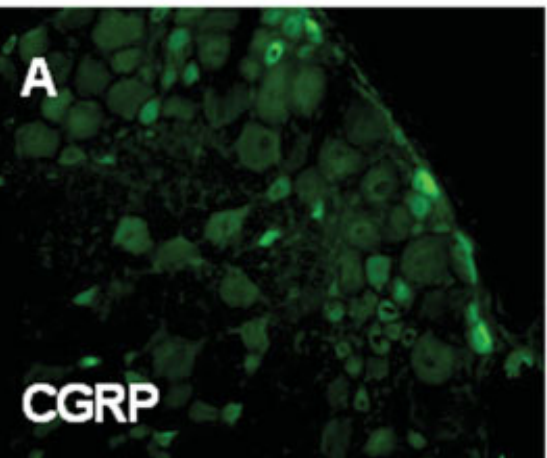

D

TNF
NS + 1d CFA
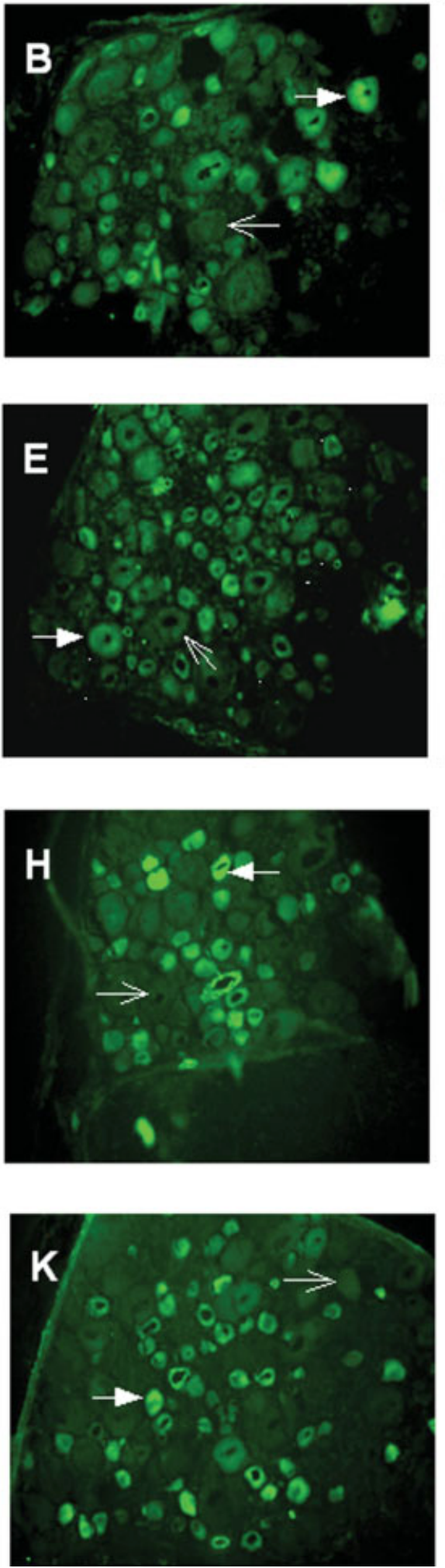

NC + 1d CFA
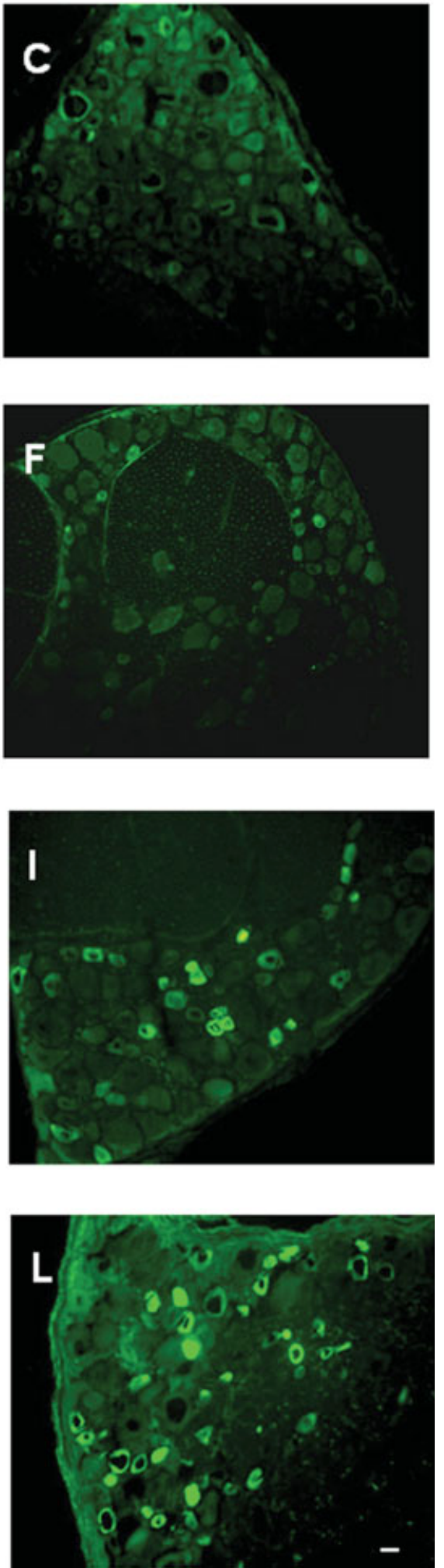

Fig. 5. Photomicrographs showing CGRP-, TNF-, TRPV-1, and IL-10 IR in ipsilateral L4 DRG from controls $(\mathbf{A}, \mathbf{D}, \mathbf{G}, \mathbf{J}$, respectively), 1 day after CFA (B,E, $\mathbf{H}, \mathbf{K}$, respectively), and with NC pretreatment $(\mathbf{C}, \mathbf{F}, \mathbf{I}, \mathbf{L}$, respectively). Arrows for positive and arrowheads for negative neurons. Scale bar $=20 \mu \mathrm{m}$. 


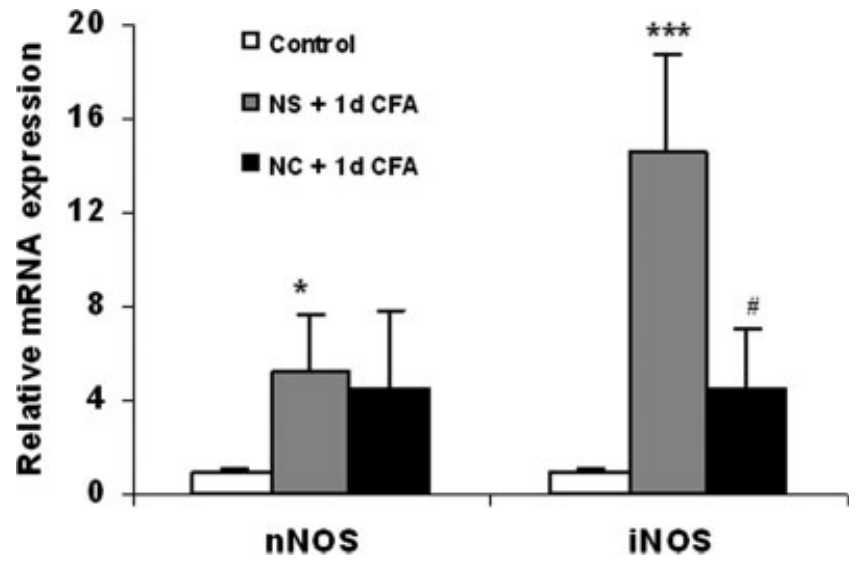

Fig. 6. Spinal cord nNOS and iNOS mRNA as measured with realtime PCR. nNOS and iNOS mRNA were increased after i.pl. CFA compared with controls $\left({ }^{\star} P<0.05\right.$ and $\left.\star \star \star P P<0.001\right)$. Pretreatment with $30 \mu \mathrm{g}$ NC significantly reduced the up-regulation of iNOS mRNA ( ${ }^{\#} P<0.05$ compared with CFA group) but not of nNOS mRNA. Repeated-measures ANOVA followed by Tukey test was used to detect differences between groups ( $\mathrm{n}=6$ for each group).

2006) but also in the early phase. Considering the antinociceptive effects of $\mathrm{NC}$ in the present study, the activation of the NC/ORL1 receptor system in DRG after CFA may be involved in the suppression of both the development and the maintenance of CFA-induced nociceptive hypersensitivity. After CFA, NC was specifically reduced in some classes of small neurons and increased in a single group of medium-sized neurons. Thus, after inflammation, a phenotypic change for NC occurred like that previously observed for other mediators (Zhou et al. 1999; Schäfers et al., 2003). Phenotypic changes of DRG neurons are part of the complex system regulating pain sensation after tissue injury, so the NC/ORL1 receptor system may modulate local circuitry of nociceptive hypersensitivity.

The induction of ATF3, which can be used as a maker of nerve injury (Tsujino et al., 2000), is part of the cellular response after nerve injury. Given that a subpopulation of NC- and ORL1 receptor-IR neurons was injured, the increase in immunoreactivity for both the ligand and the receptor has to be attributed to injured as well as uninjured neurons. It is still unknown whether the presence of NC and the ORL1 receptor in injured neurons or the presence in uninjured neurons should be more functionally important; however, this phenotypic change may have a role in processing of nociceptive information, as previous studies have shown (Neumann et al., 1996; Schäfers et al., 2003). The presence of ATF3 in DRG neurons 1 day after i.pl. CFA injection is in contrast to a previous finding that ATF3 mRNA in DRG neurons was not detected 3 days after i.pl. CFA (Tsujino et al., 2000) but is in accordance with more recent findings of an increase in ATF3 in DRG following CFA-induced local inflammation of sciatic nerve
(Dilley et al., 2005). Furthermore, CFA leads to an activation of c-Jun N-terminal kinase (JNK) in DRG (Doya et al., 2005), and, considering that ATF3 can be induced by the JNK (Hai and Hartman, 2001), it is conceivable that ATF3 may be induced via JNK in the CFA model.

\section{NC Suppresses the Up-Regulation of Inflammatory Mediators Induced by CFA}

I.pl. injection of CFA causes a significant elevation of CGRP and VR1 in DRG neurons (Nahin and Byers, 1994; Luo et al., 2004), which was confirmed in the present experiments and which could be inhibited by i.t. NC. A major subpopulation of the prepronociceptin (ppNC)-positive neurons shows direct juxtaposition to CGRP neurons, and ORL1 receptor is expressed with a high degree of coexpression with CGRP (Mika et al., 2003). This has led to the suggestion that NC released locally in the DRG might modulate CGRP-containing neurons in a paracrine manner via the ORL1 receptors. In our studies, NC applied i.t. might reach the DRG and act upon the ORL1 receptor-positive neurons to down-regulate CGRP expression.

Furthermore, the colocalization or close vicinity of ppNC, CGRP, and the ORL1 receptor has been suggested to result in the expression of the ORL1 receptor and NC in close vicinity also in central terminals (Mika et al., 2003). This could be a way in which NC modulates neuropeptide release in the dorsal horn by presynaptic inhibition. In fact, examples where NC could directly or indirectly inhibit the release of substance $\mathrm{P}$ (SP) and CGRP from the sensory nerve terminals have been published (for review see Giuliani et al., 2000). Thus, the i.t. application in our study might also decrease the central release of CGRP as one mechanism of antihyperalgesia. TRPV-1, which plays a critical role in the transduction of noxious chemical and thermal stimuli (Caterina et al., 1997), is colocalized with NC in a subpopulation of primary sensory neurons (Itoh et al., 2001). The release of the neuropeptides SP and CGRP from the capsaicin-sensitive afferent nerve terminals is attenuated by nociceptin, such that nociceptin reduced the proinflammatory effect of TRPV-1 activation (Nemeth et al., 1998). Our present study suggests that the attenuation of CGRP- and TRPV-1-mediated transmission by $\mathrm{NC}$, in an ORL1 receptor-mediated manner, may contribute to its antinociceptive effects.

Numerous studies provide evidence that proinflammatory cytokines such as TNF, IL-1, and IL-6 induce or facilitate inflammatory as well as neuropathic pain and hyperalgesia (Sommer and Kress, 2004). The antiinflammatory cytokine IL-10, which can suppress proinflammatory cytokine production, exhibits antinociceptive effects in different pain models (Wagner et al., 1998; Milligan et al., 2005). It was previously demonstrated that TNF expression is elevated in spinal cord (Raghavendra et al., 2004) and locally in the inflamed paw after CFA (Woolf et al., 1997). Here, TNF was dramatically up-regulated in DRG neurons after CFA, which is in 
line with previous reports (Woolf et al., 1997; Raghavendra et al., 2004). Opioids and cytokines interact in pain modulation (Laughlin et al., 2000; Walker, 2003; Rittner and Stein, 2005). Cytokines such as IL-1 $\beta$ and TNF increase NC mRNA expression in astrocytes (Buzas et al., 2002). Conversely, the increased production of IL-1 and TNF in brain neurons and microglia and in peritoneal macrophages induced by trauma was reversed by NC (Zhao et al., 2002a,b). Considering that TNF contributes to the development of inflammatory pain and that IL-10 exhibits antihyperalgesic effects, the reduction of TNF by NC through the ORL1 receptor combined with a lack of suppression of IL-10 may be part of the mechanism by which NC reduces inflammatory pain.

$\mathrm{NO}$, an inter- and intracellular messenger molecule in the peripheral and central nervous system, is involved in inflammatory pain (Handy and Moore, 1998). Here, we found that nNOS and iNOS mRNA, were up-regulated in the spinal cord following CFA injection, confirming previous studies (Wu et al., 1998; Tao et al., 2003). NC significantly reversed the increase of iNOS mRNA (present predominantly in astrocytes and microglia) but had no effect on nNOS mRNA (localized mainly in neurons). Our results raise the possibility that the analgesic effect of NC in inflammatory pain is mediated by inhibition of $\mathrm{NO}$ production in glial cells, but not in neurons. On the other hand, Mabuchi et al. (2003) demonstrated that nNOS is involved in the analgesic effect of JT-801, a selective NC antagonist, in neuropathic pain. This implies that different types of NOS may participate in different pathways of NC-related pain modulation.

\section{CONCLUSIONS}

In summary, we have provided evidence that pretreatment with i.t. NC significantly reduces the development of CFA-induced pain behavior in rats. Elevated NC and ORL1 receptor in DRG after CFA may represent an endogenous mechanism that modulates inflammatory pain. Several lines of evidence suggest that a reduction of inflammatory mediators is involved in the mechanism by which NC modulates pain behavior. Our study points to the ORL1 receptor as a target to modulate inflammatory pain.

\section{ACKNOWLEDGMENTS}

We thank Barbara Dekant, Lydia Biko, and Barbara Gado for excellent technical assistance. The authors thank K.V. Toyka for continuous support. The study was supported by research funds of the University of Würzburg.

\section{RERERENCES}

Banner LR, Patterson PH, Allchorne A, Poole S, Woolf CJ. 1998. Leukemia inhibitory factor is an anti-inflammatory and analgesic cytokine. J Neurosci 18:5456-5462.
Buzas B, Rosenberger J, Kim KW, Cox BM. 2002. Inflammatory mediators increase the expression of nociceptin/orphanin FQ in rat astrocytes in culture. Glia 39:237-246.

Calo G, Guerrini R, Rizzi A, Salvadori S, Regoli D. 2000. Pharmacology of nociceptin and its receptor: a novel therapeutic target. Br J Pharmacol 129:1261-1283.

Caterina MJ, Schumacher MA, Tominaga M, Rosen TA, Levine JD, Julius D. 1997. The capsaicin receptor: a heat-activated ion channel in the pain pathway. Nature 389:816-824.

Chen Y, Sommer C. 2006. Nociceptin and its receptor in rat dorsal root ganglion neurons in neuropathic and inflammatory pain models: implications on pain processing. J Periph Nerv Syst 11:232-240.

Dilley A, Lynn B, Pang SJ. 2005. Pressure and stretch mechanosensitivity of peripheral nerve fibres following local inflammation of the nerve trunk. Pain 117:462-472.

Doya $\mathrm{H}$, Ohtori S, Fujitani M, Saito T, Hata K, Ino H, Takahashi K, Moriya H, Yamashita T. 2005. c-Jun N-terminal kinase activation in dorsal root ganglion contributes to pain hypersensitivity. Biochem Biophys Res Commun 16:132-138.

Giuliani S, Lecci A, Maggi CA. 2000. Nociceptin and neurotransmitter release in the periphery. Peptides 21:977-984.

Hai T, Hartman MG. 2001. The molecular biology and nomenclature of the activating transcription factor/cAMP responsive element binding family of transcription factors: activating transcription factor proteins and homeostasis. Gene 273:1-11.

Handy RL, Moore PK. 1998. Effects of selective inhibitors of neuronal nitric oxide synthase on carrageenan-induced mechanical and thermal hyperalgesia. Neuropharmacology 37:37-43.

Hargreaves K, Dubner R, Brown F, Flores C, Joris J. 1988. A new and sensitive method for measuring thermal nociception in cutaneous hyperalgesia. Pain 32:77-88.

Itoh $\mathrm{M}$, Takasaki I, Andoh $\mathrm{T}$, Nojima $\mathrm{H}$, Tominaga $\mathrm{M}$, Kuraishi $\mathrm{Y}$. 2001. Induction by carrageenan inflammation of prepronociceptin mRNA in VR1-immunoreactive neurons in rat dorsal root ganglia. Neurosci Res 40:227-233.

Jia Y, Linden DR, Serie JR, Seybold VS. 1998. Nociceptin/orphanin FQ binding increases in superficial laminae of the rat spinal cord during persistent peripheral inflammation. Neurosci Lett 250:21-24.

Kleinschnitz C, Brinkhoff J, Zelenka M, Sommer C, Stoll G. 2004. The extent of cytokine induction in peripheral nerve lesions depends on the mode of injury and NMDA receptor signaling. J Neuroimmunol 149:77-83.

Laughlin TM, Bethea JR, Yezierski RP, Wilcox GL. 2000. Cytokine involvement in dynorphin-induced allodynia. Pain 84:159-167.

Levine JD, Fields HL, Basbaum AI. 1993. Peptides and the primary afferent nociceptor. J Neurosci 13:2273-2286.

Luo H, Cheng J, Han JS, Wan Y. 2004. Change of vanilloid receptor 1 expression in dorsal root ganglion and spinal dorsal horn during inflammatory nociception induced by complete Freund's adjuvant in rats. Neuroreport 15:655-658.

Mabuchi T, Matsumura S, Okuda-Ashitaka E, Kitano T, Kojima H, Nagano T, Minami T, Ito S. 2003. Attenuation of neuropathic pain by the nociceptin/orphanin FQ antagonist JTC-801 is mediated by inhibition of nitric oxide production. Eur J Neurosci 17:1384-1392.

Meunier JC, Mollereau C, Toll L, Suaudeau C, Moisand C, Alvinerie P, Butour JL, Guillemot JC, Ferrara P, Monsarrat B, Mazarguil H, Vassart G, Parmentier M, Costentin J. 1995. Isolation and structure of the endogenous agonist of opioid receptor-like ORL1 receptor. Nature 377:532-535.

Mika J, Li Y, Weihe E, Schafer MK. 2003. Relationship of pronociceptin/orphanin FQ and the nociceptin receptor ORL1 with substance P and calcitonin gene-related peptide expression in dorsal root ganglion of the rat. Neurosci Lett 348:190-194. 
Milligan ED, Langer SJ, Sloane EM, He L, Wieseler-Frank J, O'Connor K, Martin D, Forsayeth JR, Maier SF, Johnson K, Chavez RA, Leinwand LA, Watkins LR. 2005. Controlling pathological pain by adenovirally driven spinal production of the anti-inflammatory cytokine, interleukin-10. Eur J Neurosci 21:2136-2148.

Mogil JS, Pasternak GW. 2001. The molecular and behavioral pharmacology of the orphanin $\mathrm{FQ} /$ nociceptin peptide and receptor family. Pharmacol Rev 53:381-415.

Nahin RL, Byers MR. 1994. Adjuvant-induced inflammation of rat paw is associated with altered calcitonin gene-related peptide immunoreactivity within cell bodies and peripheral endings of primary afferent neurons. J Comp Neurol 349:475-485.

Nemeth J, Helyes Z, Oroszi G, Than M, Pinter E, Szolcsanyi J. 1998. Inhibition of nociceptin on sensory neuropeptide release and mast cellmediated plasma extravasation in rats. Eur J Pharmacol 347:101-104.

Neumann S, Doubell TP, Leslie T, Woolf CJ. 1996. Inflammatory pain hypersensitivity mediated by phenotypic switch in myelinated primary sensory neurons. Nature 384:360-364.

Raghavendra V, Tanga FY, DeLeo JA. 2004. Complete Freunds adjuvantinduced peripheral inflammation evokes glial activation and proinflammatory cytokine expression in the CNS. Eur J Neurosci 20:467-473.

Reinscheid RK, Nothacker HP, Bourson A, Ardati A, Henningsen RA, Bunzow JR, Grandy DK, Langen H, Monsma FJ Jr, Civelli O. 1995. Orphanin FQ: a neuropeptide that activates an opioid like G proteincoupled receptor. Science 270:792-794.

Rittner HL, Stein C. 2005. Involvement of cytokines, chemokines and adhesion molecules in opioid analgesia. Eur J Pain 9:109-112.

Rosen A, Lundeberg T, Bytner B, Nylander I. 2000. Central changes in nociceptin dynorphin B and Met-enkephalin-Arg-Phe in different models of nociception. Brain Res Brain Res Rev 857:212-218.

Schäfers M, Geis C, Svensson CI, Luo ZD, Sommer C. 2003. Selective increase of tumour necrosis factor- $\alpha$ in injured and spared myelinated primary afferents after chronic constrictive injury of rat sciatic nerve. Eur J Neurosci 17:791-804.

Sommer C, Kress M. 2004. Recent findings on how proinflammatory cytokines cause pain: peripheral mechanisms in inflammatory and neuropathic hyperalgesia. Neurosci Lett 361:184-187.

Tao F, Tao YX, Mao P, Zhao C, Li D, Liaw WJ, Raja SN, Johns RA. 2003. Intact carrageenan-induced thermal hyperalgesia in mice lacking inducible nitric oxide synthase. Neuroscience 120:847-854.
Terenius L, Sandin J, Sakurada T. 2000. Nociceptin/orphanin FQ metabolism and bioactive metabolites. Peptides 21:919-922.

Tsujino H, Kondo E, Fukuoka T, Dai Y, Tokunaga A, Miki K, Yonenobu K, Ochi T, Noguchi K. 2000. Activating transcription factor 3 (ATF3) induction by axotomy in sensory and motoneurons: A novel neuronal marker of nerve injury. Mol Cell Neurosci 15:170-182.

Wagner R, Janjigian M, Myers RR. 1998. Anti-inflammatory interleukin-10 therapy in CCI neuropathy decreases thermal hyperalgesia, macrophage recruitment, and endoneurial TNF- $\alpha$ expression. Pain 74:3542 .

Walker JS. 2003. Anti-inflammatory effects of opioids. Adv Exp Med Biol 521:148-160.

Woolf CJ, Chong MS. 1993. Preemptive analgesia-treating postoperative pain by preventing the establishment of central sensitization. Anesth Analg 77:362-379.

Woolf CJ, Allchorne A, Safieh-Garabedian B, Poole S. 1997. Cytokines, nerve growth factor and inflammatory hyperalgesia: the contribution of tumour necrosis factor $\alpha$. Br J Pharmacol 121:417-424.

Wu J, Lin Q, Lu Y, Willis WD, Westlund KN. 1998. Changes in nitric oxide synthase isoforms in the spinal cord of rat following induction of chronic arthritis. Exp Brain Res 118:457-465.

Xu X, Grass S, Hao J, Xu IS, Wiesenfeld-Hallin Z. 2000. Nociceptin/ orphanin FQ in spinal nociceptive mechanisms under normal and pathological conditions. Peptides 21:1031-1036.

Yaksh TL, Rudy TA. 1976. Analgesia mediated by a direct spinal action of narcotics. Science 192:1357-1358.

Yamamoto T, Ohtori S, Chiba T. 2000. Effects of pre-emptive administered nociceptin on the development of thermal hyperalgesia induced by two models of experimental mononeuropathy in the rat. Brain Res 871:192-200.

Zhao H, Huang HW, Wu GC, Cao XD. 2002a. Effect of orphanin FQ on interleukin-1beta mRNA transcripts in the rat CNS. Neuroscience 114:1019-1031.

Zhao H, Wu GC, Cao XD. 2002b. Immunomodulatory activity of orphanin FQ/nociceptin on traumatic rats. Acta Pharmacol Sin 23:343348.

Zhou XF, Chie ET, Deng YS, Zhong JH, Xue Q, Rush RA, Xian CJ. 1999. Injured primary sensory neurons switch phenotype for brainderived neurotrophic factor in the rat. Neuroscience 92:841-853. 